\title{
DESIGN NO ESPAÇO PÚBLICO: O MOBILIÁRIO DA ACADEMIA DA PRIMEIRA IDADE NA VISÃO DOS SEUS USUÁRIOS
}

Andrea de Brito Stefanelli Vieira

Faculdade de Arquitetura e Urbanismo da Universidade de São Paulo- FAUUSP

andrea.vieira@usp.br

Cibele Haddad Taralli, Dra

Faculdade de Arquitetura e Urbanismo da Universidade de São Paulo- FAUUSP

cibelet@usp.br

Resumo: Este trabalho pretende apresentar algumas considerações sobre o mobiliário urbano, tendo como recorte os equipamentos da Academia da Primeira Idade (A.P.I.), recém implantados nas áreas de playground dos espaços públicos de lazer em praças e parques da cidade de São Paulo. Investiga e analisa por meio de uma pesquisa de campo piloto, o design deste mobiliário (A.P.I.) em termos funcionais, formais, comportamentais e de interações sociais, focando aspectos de uso e apropriação pelos usuários, considerando também suas relações de implantação no espaço público. Busca-se compreender de forma complementar como o mobiliário urbano pode contribuir para melhorar a qualidade do espaço público de lazer. Utiliza ferramentas de pesquisa qualitativa para captar e caracterizar a relação desses produtos com seus usuários (crianças e seus acompanhantes) nos locais selecionados. Através da confrontação de dados obtidos de referenciais teóricos; de observação não participante; de entrevistas com usuários adultos e acompanhantes das crianças; e da aplicação de storytelling (por meio de tema para redação) com crianças, procurou-se discutir a pertinência destas ferramentas na obtenção dos resultados, a fim de dar continuidade a outros estudos de casos em diferentes locais de implantação. Como considerações preliminares apresentam-se formas de uso diferenciadas, além de referências positivas e negativas nas atividades previstas e expressas pelos usuários, sinalizando a possibilidade de obtenção de parâmetros e opiniões que podem ser aplicadas a novas implantações e novos projetos de mobiliário urbano neste segmento, além da manutenção de sua utilização atual, considerando a importância social de equipamentos de lazer para a população da cidade.

Palavras-chave: espaço público, mobiliário urbano, playground, design de equipamento urbano, Academia da Primeira Idade

Abstract: This paper presents some considerations on urban furniture, looking at the First Age Academy (F.A.A.) equipment, recently implanted in playground areas located in public spaces for leisure, in squares and parks 
of the city of São Paulo. It investigates and analyzes, through a pilot field research, the design of this furniture (F.A.A.) in functional, formal, behavioral and social interactions terms, focusing on aspects of use and appropriation by users, also considering its implantation relations in public space. In a complementary manner, we try to understand how urban furniture can help to improve the quality of public leisure space. We used qualitative research tools to capture and characterize the relationship of these products with their users (children and their companions) in selected locations. Through the confrontation of data obtained by theoretical referential, as well as non-participant observation, interviews with adult users and caregivers of children and the application of storytelling (through a theme for writing) with children, we tried to discuss the relevance of these tools in the achievement of the results, in order to proceed with other case studies in different potential locations for deployment. As preliminary considerations, are presented differentiated forms of use, as well as positive and negative references in the planned activities and expressed by users, signaling the possibility of obtaining parameters and opinions that can be applied to new implantations and new urban furniture projects in this segment, in addition to maintaining its current use, considering the social importance of leisure equipment for the population of the city.

Keyword: public space, urban furniture, playground, urban equipment design, First Age Academy

\section{INTRODUÇÃO}

Os espaços livres públicos, para o lazer e a fruição na cidade contemporânea são considerados vitais para a vida cotidiana. Nele usuários adultos e crianças desenvolvem atividades relacionadas ao lazer, exercitando o corpo, mente, ou em ações para a diversão e a contemplação, benéficas para a qualidade de vida urbana, distintas das horas de trabalho dirigidas ou planejadas. As praças e parques públicos, com áreas para brincar, sentar, se exercitar, passear cumprem este papel na cidade. Todos os elementos que os constituem, como pisos, mobiliário urbano de recreação e lazer, infraestrutura para o uso, além do paisagismo são importantes para qualificar, e propiciar a apropriação do local.

O conceito de espaço como totalidade, como instância social, considerado como conjunto indissociável de um sistema de objetos e de ações, incluindo materialidade e sociedade, como colocado por SANTOS (1996) é adotado neste artigo, que busca o entendimento das relações entre um objeto, aqui focado num equipamento de mobiliário urbano - instalação para playground, com os usuários no seu espaço de implantação. Segundo o mesmo autor, neste espaço estes sistemas interagem constantemente, e seus elementos constituídos por objetos, condicionam a forma da ação colocando que "A ação é tanto mais eficaz quando os objetos são mais adequados" (SANTOS, 1996), sendo que estas podem levar a criação de novos objetos ou se realizar sobre objetos existentes.

Já espaço livre é definido como aquele existente na área urbana livre, não coberta e sem edificações como ruas, praças, parques, praias, rios, campos (MAGNOLI, 
2006). Estes espaços podem ser classificados; de circulação como ruas e calçadas, ou local de permanência de lazer e recreação como as praças e parques. São considerados propriedades de uso comum do povo, com acesso livre, irrestrito e com possibilidade de interações entre os usuários em diversos tipos de atividades e geralmente têm sua administração, implantação, manutenção e inserção de equipamentos realizada pelos órgãos públicos.

Os espaços públicos podem propiciar relações de afetividade, identidade coletiva e sentimentos de pertencimento importantes para seus usuários (QUEIROGA, 2012). A observação direta sobre o uso que cidadãos fazem dos espaços pontua e ressalta a importância do mobiliário urbano e seus locais de implantação, colocando a indagação sobre como, o que, e quais são os elementos que devem ser considerados no projeto (de produtos e do local físico) para atender as necessidades e expectativas dos usuários. Do ponto de vista do design e da arquitetura, busca-se compreender como o mobiliário urbano pode contribuir para melhorar a qualidade do espaço público de lazer sob o enfoque dos seus usuários.

Este estudo tem como recorte a análise de um conjunto de equipamentos recém implantados na área do playground em algumas praças e parques da cidade de São Paulo, denominado Academia da Primeira Idade (A.P.I.), que tem como público usuário as crianças e seus responsáveis que utilizam este espaço.

Segundo Oliveira (2004), o espaço público urbano de uso multifuncional, tem papel fundamental na formação das crianças. É o local de todos, sem restrições, que atende a várias funções, como encontrar amigos, brincar (atividade ao qual a criança exercita sua sensibilidade, sua coordenação motora, sua mente e criatividade), passear, praticar esportes, além de ser importante local de contato com a natureza, com outras pessoas na troca de valores e socialização.

Acredita-se que equipamentos adequados à criança colaboram para seu processo de aprendizado, de desenvolvimento físico, cognitivo e de construção de laços socioculturais fundamentais para seu desenvolvimento.

Da observação do cotidiano no uso do espaço público de lazer, em determinadas praças e parques, visualiza-se atualmente na cidade de São Paulo a tendência de substituição; e ou convivência entre brinquedos tradicionais (balança, gangorra, escorregador, trepa-trepa) do playground com novos equipamentos na categoria de academia denominados A.P.I. Apesar de existirem normas que regem os brinquedos de playground, a NBR 16071 em sua introdução diz que estas não se aplicam a equipamentos de academia. (ABNT, 2012).

Segundo Queiroga (2012) desde o final do século XX, vem sendo observado um crescente estímulo de interesse das populações urbanas pelas atividades físicas, que pode ser visto através da proliferação de academias de variados tipos e pela ocupação de canteiros e ruas públicas para corrida, caminhadas e também para andar de bicicleta.

O Programa Brasil Saudável do Ministério da Saúde traz justificativa para implantação das Academias ao Ar Livre em Curitiba, e (A.T.I) Academias da Terceira Idade em Maringá, sendo estas consideradas como ferramentas de lazer, saúde e atividade física (GATA et al. 2015). Ainda não foram encontrados dados sobre as políticas públicas de implantação das A.P.I., mas segundo fontes jornalísticas surgiram primeiro as A.T.I. na cidade de Maringá (PR) em 2006, e implantada a primeira unidade 
de A.P.I em 2008, e depois difundidas para outros municípios brasileiros (MARINGÁ,2008).

Segundo nomenclatura da empresa relatada como pioneira destes projetos, (ZIOBER, 2015) o conjunto de produtos denominados "Academia ao Ar Livre" tem variações em função de determinados públicos, como para a terceira idade (A.T.I); para jovens adultos (A.J.A); para cadeirantes (A.P.C) e para crianças (A.P.I), consideradas nesta pesquisa como equipamentos de mobiliário urbano. A ABNT (1986) - NBR 9283, considera mobiliário urbano como: "todos os objetos, elementos e pequenas construções integrantes da paisagem urbana, de natureza utilitária ou não, implantada mediante autorização do poder público em espaços públicos e privados".

Outros trabalhos sinalizam a importância deste estudo, na busca pela relação do objeto com o usuário no espaço de implantação, conforme John (2010) salienta que o mobiliário urbano deve ser considerado de maneira contextualizada, e não somente estudado como objeto isolado, mas em conjunto com os demais elementos da paisagem. Outros autores como Nomura (2006) e Mourthé (2008) colocam a importância em considerar os elementos instalados como um conjunto relacionado ao entorno, aos usuários e aos demais produtos e instalações existentes, além de conferirem importância à própria disposição física no local de implantação para a perfeita integração do equipamento com o espaço urbano.

O objetivo deste estudo é buscar por meio de ferramentas de pesquisa qualitativa, de observação técnica e de levantamento as opiniões das crianças e seus responsáveis, com enfoque no uso e apropriação, caracterizar a relação dos produtos da A.P.I. com os usuários no espaço de implantação.

Adotado como estudo de caso uma pesquisa exploratória realizada no parque Cândido Portinari e na praça Barão de Japurá, respectivamente nas zonas oeste e sul de São Paulo, para aproximação com o usuário, utilizando das seguintes ferramentas de pesquisa: observação não participante; entrevista com usuário adulto; questionário e storytelling (redação) com crianças, para captação de suas percepções e necessidades.

A substituição e o uso de novos produtos no espaço público urbano sugerem a necessidade de verificação e acompanhamento desta iniciativa, não só relacionada à segurança técnica (de normas e regulamentos) como também de percepções acerca de seu uso e aceitação, partindo do pressuposto de que quando o usuário utiliza um equipamento de forma diferente da proposta, ele está falando não com palavras, mas através de ações que sinalizam se a proposta oferecida está ou não adequada as suas expectativas. Esta pesquisa pretende relatar analisar e dar voz a estas ações dos usuários, essenciais para novos produtos ou aperfeiçoamento desses equipamentos de lazer e atividades físicas que compõem o mobiliário urbano.

\section{DESENVOLVIMENTO}

No levantamento de dados em campo, utilizou-se a ferramenta da observação não participante (elegendo as categorias - olhar, ouvir e perceber) como forma de aproximação ao usuário para registro, análise e interpretação do binômio ação/ comportamento e formas de uso, visando identificar padrões recorrentes e divergentes. Segundo Gray (2012) a observação proporciona a oportunidade de ir além das opiniões das pessoas, aproximando-se assim de uma avaliação de ações práticas. 
Foram realizadas visitas em dias e horários distintos nos ambientes escolhidos (praça Barão de Japurá e parque Cândido Portinari), utilizando os procedimentos de fotos e filmagens dos usuários na sua atividade de lazer, seguidas de observação e análise do comportamento espontâneo; e de aspectos de uso e apropriação dos equipamentos no espaço público em questão.

Para captar a opinião dos usuários adultos foi utilizada a ferramenta de entrevista estruturada, que segundo Flick (2012) tem como objetivo obter as visões individuais dos entrevistados sobre um tema, conseguindo assim elementos de comportamento ou atitude sobre uma questão examinada. $O$ instrumental elaborado apresentava seis perguntas sobre os seguintes aspectos: necessidades e expectativas dos usuários; espaço de implantação; interação social; aspectos de configuração formal dos produtos; adequação e aspectos funcionais; além da percepção do entrevistado sobre a sua consideração destes como brinquedo ou academia. Para as crianças dos adultos respondentes (de um total seis respondentes) foi solicitada autorização para a elaboração de um pequeno texto quando maiores de nove anos; e quando menores foi feita a pergunta do que mais gostaram e menos gostaram ao utilizar os equipamentos em questão.

Como forma de aproximação ao usuário criança, utilizou-se da ferramenta do storytelling, (que capta versões individuais subjetivas, podendo ser até fantasiosas e trazendo experiências vivenciadas), apresentadas na forma de questionário com respostas abertas e tema para redação. Foi aplicado durante uma aula de técnicas de redação em uma escola particular na zona sul de São Paulo, com praças nas suas imediações, que já contêm os equipamentos da A.P.I., e realizada com crianças de nove e dez anos por já se expressam através da escrita. $O$ tema para redação proposta foi: Brincando como os brinquedos do parquinho público, tendo como questão, aspectos da preferência e da experiência nos brinquedos. Como respondentes obtevese um total de sete crianças.

Sobre o local de implantação na praça Barão de Japurá observou-se entorno tipicamente residencial composto de prédios, casas e pouco comércio. Em uma das extremidades localiza-se um edifício público que funciona como centro de educação infantil (CEI). No espaço interno da praça encontra-se alguma vegetação e equipamentos para crianças, jovens e idosos. Do lado oposto à CEI estão os equipamentos infantis na configuração do padrão da A.P.I. multifuncional, escada torcida e carrossel (substituindo os balanços tradicionais e a gaiola trepa-trepa da área do playground) que convivem com um escorredor e gangorra de madeira tradicional.

Já o parque Cândido Portinari tem em funcionamento na sua área destinada ao playground somente equipamentos da A.P.I. como alternativa para brincar, implantado em uma caixa de areia que propicia muita brincadeira e uso pelas crianças. O local apresenta pouca vegetação e proteção ao sol, tem pequenos quiosques com mesa e bancos e está localizada próxima a área da administração, que conta com profissional fazendo continuamente a segurança e inibindo maus usos dos equipamentos. Logo ao lado da área deste playground estão implantados equipamentos para jovens adultos. Também foi questionado aos usuários responsáveis a conveniência desta forma de implantação das áreas das academias dos adultos localizadas próximas ao espaço do playground, e se isto facilitaria o uso enquanto a criança brincaria no equipamento ao lado. 


\subsection{Apresentação das categorias elencadas da observação e entrevista com os adultos}

\subsubsection{Formas de uso e apropriação}

Foram elencados alguns equipamentos do conjunto da A.P.I. para análise: o multifuncional (fig.1), carrossel (fig. 3) e gangorra equilibrista (fig. 4).

O equipamento denominado Multifuncional apresenta cinco funções (ver fig. 1) contendo um escorregador formado por dois tubos paralelos, espaçados em dezoito e meio centímetros aproximadamente entre si (5), onde a atividade "de escorregar" seria feita com o deslizamento das pernas pelos dois tubos, sem nenhum apoio para as mãos. Observou-se que este ato de escorregar não é realizado por todas as crianças, sendo que algumas apresentam dificuldades nesta atividade devido ao atrito do corpo ou roupa, outras manifestaram receio ou medo de tentar descer devido a altura de aproximadamente dois metros entre a parte superior e o nível do solo, e descem a escada de acesso de volta; outras encaixam as pernas e deitam as costas no tubo para ajudar o apoio com os braços. Algumas crianças ainda tentam escalar o tubo com as mãos e pés no sentido ascendente, talvez no mesmo intuito de escalada no sentido contrário realizado no tradicional escorregador. Também foram visualizadas crianças descendo de bruços (ver imagens na fig. 2).

1. Argolas Fixas

2. Argolas giratórias

3. Gira-gira

4. Escorregador de Rosca

5. Escorregador
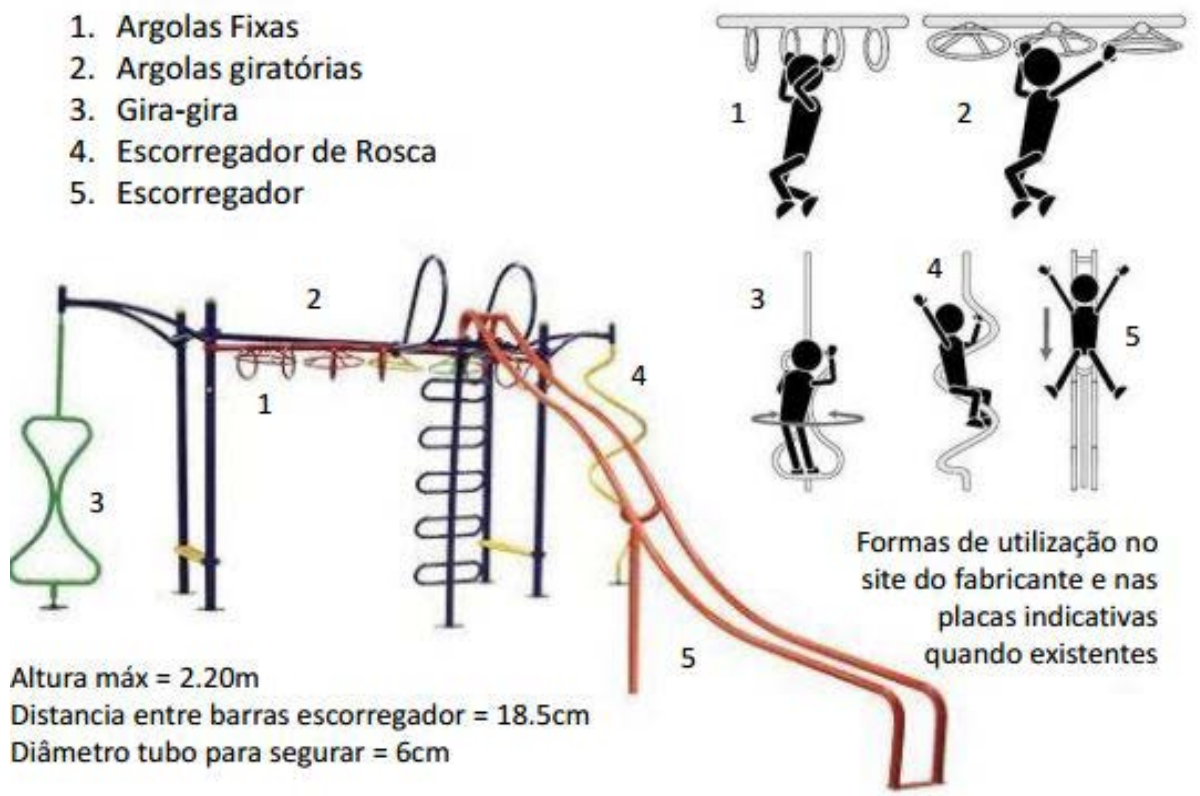

Figura 1 - Equipamento A.P. I. Multifuncional e suas formas de uso

Fonte: adaptado de imagens site: zioberbrasil.com.br (acessado nov. 2014)

As argolas giratórias (2) seriam utilizadas para desenvolver um percurso da criança em posição pendurada aproveitando do giro das argolas. No período de observações foi difícil visualizar alguma criança conseguindo completar o percurso conforme o projetado. Muitas vezes as crianças se penduravam na primeira argola e acabavam batendo o corpo na própria haste de sustentação do brinquedo, sem conseguir se lançar para a próxima argola. Foi observado, que muitas não têm força nos braços para continuar o percurso e acabam caindo de pé no chão.

Na parte denominada gira-gira (3) é proposto que a criança coloque os pés na base inferior e faça movimentos de aproximação e afastamento dos braços para 
continuar o giro. Algumas preferem serem colocadas apoiadas sentadas na base horizontal superior e serem giradas pelos responsáveis, ver fig. 2.

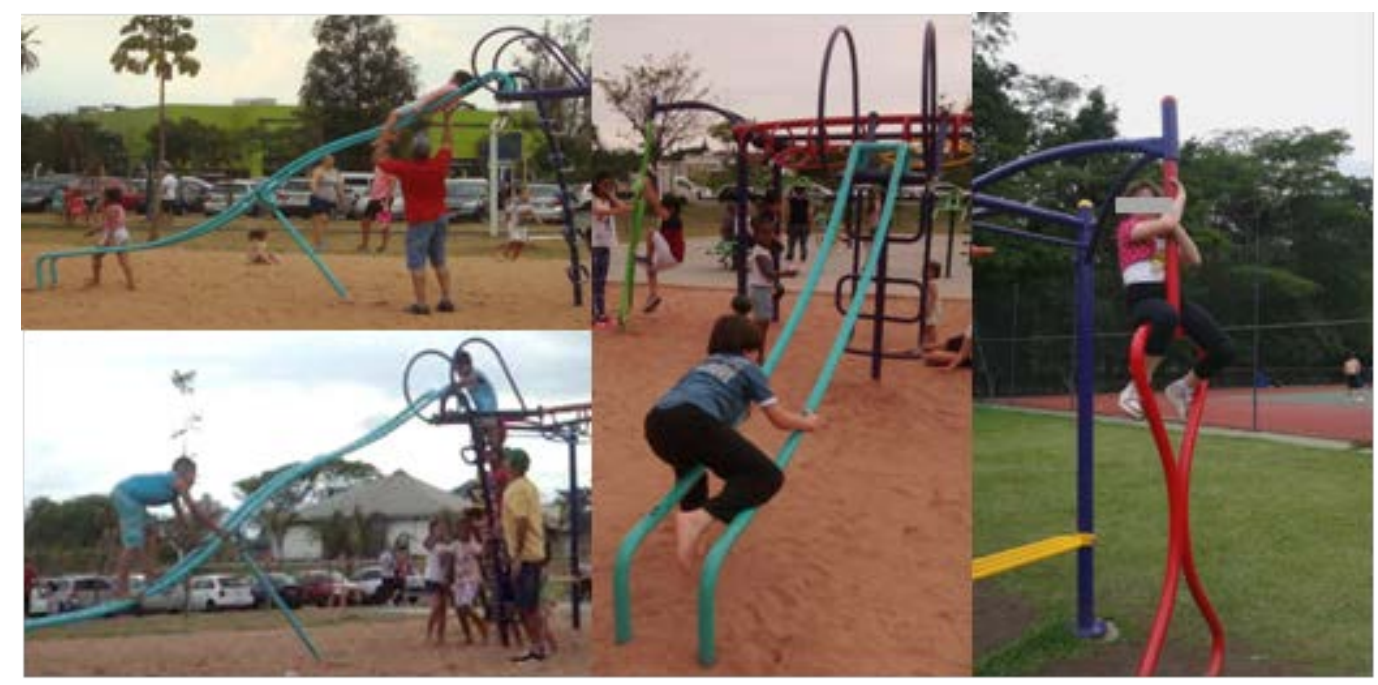

Figura 2 - Multifuncional e suas formas de uso visualizadas "in loco" Fonte: elaborado pelo autor, com base na pesquisa realizada em 2015

A parte denominada argola fixa (1) propõe o desafio de completar um percurso utilizando os braços e mãos para se segurar. O trajeto é interrompido pela escada do escorregador gerando conflito de uso principalmente quando outras crianças estão utilizando a escada de acesso.

Alguns pais diante deste brinquedo apresentam insegurança de não saber como orientar a criança em quais as possibilidades para brincar, outros, ao contrário, demonstram incentivar a criança para superar o desafio.
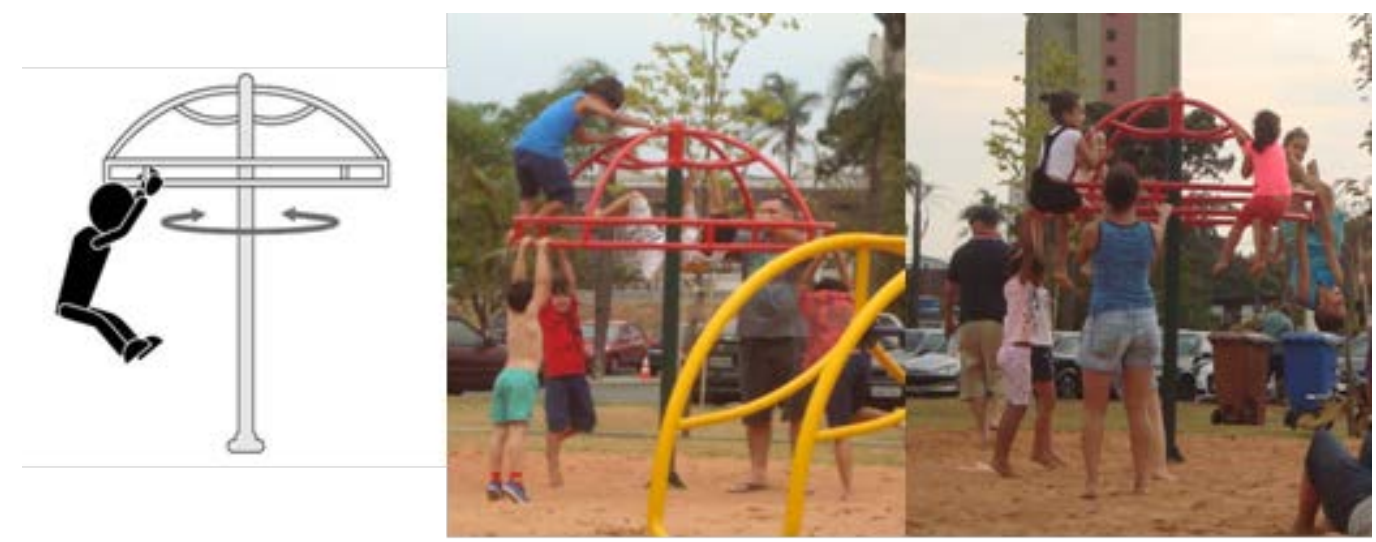

Figura 3 - Carrossel e suas formas de uso.

Fonte: elaborado pelo autor e adaptado de imagens site: zioberbrasil.com.br (acessado nov. 2014)

Outra explicação para a forma diferenciada de utilização seria a semelhança de alguns desses equipamentos com os já conhecidos em playgrounds tradicionais, desta forma o uso já é previsível.

O equipamento carrossel, ver fig. 3, projetado para ser utilizado se pendurando com as mãos e a ajuda dos pés para o giro assemelha-se ao tradicional gira-gira, porém 
apresenta altura a partir do piso de implantação no total de dois metros, sem local para sentar. Os adultos sem opção para sentar as crianças menores acabam por colocá-las na parte superior destinada as mãos simulando um assento, deslocando a posição das mãos para as hastes verticais. Algumas crianças escalam o brinquedo como desafio para se sentarem na parte superior. Este mesmo uso diferenciado foi visualizado tanto no parque como na praça em estudo.

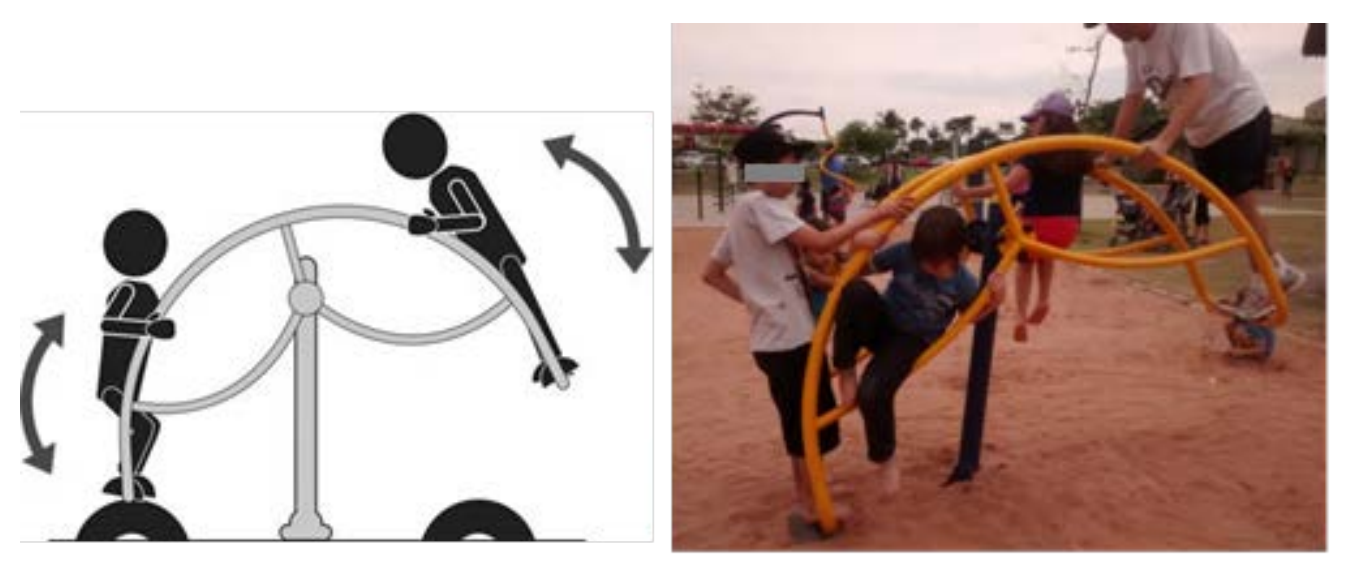

Figura 4 - Gangorra equilibrista e suas formas de uso.

Fonte: elaborado pelo autor e adaptado de imagens site: zioberbrasil.com.br (acessado nov. 2014)

O equipamento gangorra equilibrista foi projetado para ser utilizado por dois usuários, mas muitas vezes as crianças precisam de ajuda dos pais para compor o peso necessário para sua movimentação. Conforme observado quando um dos usuários sai do equipamento o outro pode levar um solavanco pela descida brusca, devido à diferença de altura de aproximadamente um metro, ver fig. 4.

Às vezes apropriações e usos informais podem se transformar em situações mais perigosas quanto à segurança no uso dos equipamentos.

Mendonça (2007) insere o conceito de apropriações formais e informais do espaço público e a importância do mapeamento dessas situações e ocorrências alternativas para fornecer subsídios que alimentem o projeto e novos equipamentos desta natureza.

\subsubsection{Espaço e contexto de implantação}

Quando feita a pergunta sobre expectativas e necessidades dos usuários adultos sobre o espaço do playground pode-se distinguir duas vertentes de respostas: uma relacionada sobre as características do local para eles, e outra para as crianças. Considera- se, portanto, que este é um espaço que deve ser pensado para a criança como público alvo, mas que deve também atender as necessidades dos responsáveis, considerando o acesso e a permanência neste espaço de forma mais segura, confortável, prazerosa e com infraestrutura adequada como uma área de lazer para ambos. $O$ item mais mencionado pelos respondentes foi relacionado ao contexto e a estrutura de implantação e à segurança do local, dentre outras como: necessidade de infraestrutura de banheiro, bebedouros, local agradável e divertido para as crianças, local preferencialmente com areia, brinquedos atrativos e interessantes, local para sentar, olhar e participar, etc. 
No parque Cândido Portinari os bancos são leves e possíveis de serem alocados próximos de onde as crianças brincam para a supervisão dos pais, e parece ser fator positivo e relevante nesta intervenção no local pelo usuário responsável.

Com relação aos equipamentos de ginástica para adultos estarem implantados no mesmo local próximo aos das crianças não houve concordância entre os entrevistados. Alguns acham positiva a possibilidade de poder se exercitar e olhar a criança ao mesmo tempo, outras acham que as crianças poderão querer utilizar os equipamentos para adultos não adequados a elas.

Segundo Oliveira (2004) a percepção da criança é diferente da do adulto, por isto é importante projetar espaço de brincar dando prioridade aos volumes, formas, materiais, texturas, elementos da natureza e cores. O espaço dever conter o maior número de contrastes para serem explorados, e brinquedos que incentivem atividades criativas e em grupo. Um local adequado poderá criar nas crianças o gosto pelo uso, pela cidade e pelo convívio com outras crianças.

Na praça Barão de Japurá a localização dos brinquedos fica do lado oposto à creche existente, onde estes usuários poderiam utilizar nos horários de entrada e saída da escola. Sua disposição muito próxima a rua também gera preocupação de alguns pais, sendo que estes poderiam estar localizados de forma mais centralizada na área da praça. Os bancos de concreto fixos não ficam muito próximos restringindo o alcance e visibilidade para os pais enquanto as crianças brincam, por isto alguns se sentam na própria estrutura do brinquedo multifuncional. O piso em terra batida da praça parece ter desvantagens com relação à caixa de areia do parque, que permite outras brincadeiras e é mais apropriado no caso de quedas.

\subsubsection{Interação social}

Com relação à categoria interação social, as opiniões se dividiram entre o equipamento favorecer ou não a brincadeira sozinha ou em grupo. Alguns equipamentos precisam de mais de uma criança para brincar, e em outros na maioria das situações observadas é necessário esperar a utilização por outra criança. Nas praças, o número de pessoas utilizando os equipamentos é muito menor do que nos parques públicos, por questões advindas de usos e hábitos urbanos nas cidades contemporâneas em relação ao espaço público e não do equipamento em si.

\subsubsection{Aspectos de configuração formal}

Na descrição sobre o formato, aparência e dimensão foram possíveis dividir as respostas em positivas e negativas. Destacando os aspectos negativos apresentados nos depoimentos relato dos pais, foram encontradas menções ao não entendimento de sua configuração associada às possibilidades de realizar atividades (atribuídas à complexidade formal), de dimensionamento, entre outros aspectos, o que leva a dificuldade de entender como brincar; e de não passar muita segurança no uso. Também foram apresentados vários relatos positivos como: interessante, chamam atenção das crianças, coloridos, bonitos, dinâmicos, inovadores, etc.

\subsubsection{Adequação e aspectos funcionais}

Nesta categoria os respondentes destacaram várias questões a serem analisadas para uma possível melhoria da comunicação dos equipamentos como 
brinquedo, atividade, etc. Declarações como: ver outras crianças elucida saber como usar, dificuldade de entender o que fazer; receio dos pais no escorregador vazado por não ter onde segurar e auxilio dos pais na utilização do brinquedo, foram constantes.

\subsubsection{Percepção sobre brinquedo ou academia}

Sobre a compreensão deste mobiliário urbano nas categorias brinquedo versus academia, a maioria dos entrevistados entende que estes novos equipamentos são brinquedos de playground e não objetos ou equipamentos de academia (relacionada ao esporte ou exercício físico). Todos os entrevistados não conheciam o nome do conjunto como Academia da Primeira Idade. Acham o nome interessante, mas prefeririam chamar as crianças para brincar nos brinquedos do playground do que ir brincar na academia.

\subsection{Apresentação das categorias elencadas do questionário e storytelling com crianças}

$\mathrm{Na}$ sala de redação de um total de quarenta crianças somente quatro conheciam e já tinham experimentado os novos equipamentos. Obtiveram-se sete respondentes no total entre os usuários no parque e aula de redação. Verifica-se a necessidade de maior número de respondentes crianças para poder ampliar os dados e validar melhor esta ferramenta.

\subsubsection{Experiência com os brinquedos}

As crianças não têm muito vocabulário para descrever em detalhes sobre como é brincar nestes brinquedos, porém a resposta mais clássica é que são legais e divertidos, portanto agradam a maioria dos respondentes. O item mais relevante a ser considerado é de que alguns são fáceis e outros são mais difíceis de usar. Como os equipamentos requerem habilidades físicas e motoras distintas, mesmo sem trazer isso claro na comunicação que os locais oferecem (como placas informativas de uso adequado por idade ou estatura; e de procedimentos para o uso) a usabilidade para algumas crianças apresenta item a ser melhor investigado.

\subsubsection{Preferência entre os brinquedos}

Quanto à preferência dos equipamentos, a opinião é bem variada. Algumas crianças dizem não gostar do escorregador e de utilizar os de pendurar, resposta que pode confirmar a observação já mencionada, talvez pelas questões de dificuldade de utilização já citadas.

Algumas crianças da idade destacada entre nove e dez anos relataram que preferem outras brincadeiras aos brinquedos do playground. E na maioria elas sempre mencionam outras crianças na brincadeira. Portanto a possibilidade de interação entre as crianças é fator importante a ser considerado em projeto de playground em espaços públicos.

\section{CONSIDERAÇÕES FINAIS}

Das respostas obtidas nas entrevistas com os responsáveis, das percepções denotadas na observação não participante e da aplicação do storytelling com crianças conhecedoras destes equipamentos, levam a opiniões positivas e negativas sobre a 
implantação e uso da A.P.I. nos espaços analisados destacando-se: o gosto mencionado por crianças na diferenciação e na novidade no brincar, ligados a aspectos de configuração com o uso de cores e movimento, ao lado de outros negativos, que mencionam dificuldades no entendimento das possibilidades e da proposta do equipamento. Somam opiniões dos responsáveis pelas crianças em apontar questões de risco e de receio no uso, bem como a insegurança, a desconfiança, o desconhecimento de limitações ou adequações ao uso por faixa etária; de habilidades desconhecidas e falta de informação no local de implantação.

Se utilizarmos como referência os desenhos apresentados no catálogo de apresentação do fabricante (Ziober, 2015) que sugere formas de utilização para os equipamentos, pode-se destacar a ocorrência de usos diferenciados para algumas tipologias, o que pode levar ao aumento da possibilidade de acidentes. Considerando que no design de produtos o uso facilitado colabora para a apropriação e a familiarização com os objetos, e que a noção de espaço público livre de uso comum deve considerar e propiciar atividades para todos os cidadãos, sua resolução formal incluindo desempenhos operativos e tecnológicos deve ser projetada para a apreensão; para uso adequado e intuitivo pelos usuários, concordando, portanto com a adoção do conceito de affordance de Norman (2006), o que poderia minimizar questões de mau uso, riscos de acidentes, entre outros aspectos. Também colaboraria para que o usuário não utilize um objeto de forma indevida ou inadequada.

Nesta pesquisa piloto, foram registradas apropriações informais, diferenciadas do pensado em projeto, como formas de uso alternativas. Estas documentações e análises podem realimentar o projeto existente, e propor requisitos chaves para novos projetos mais adequados à implantação em espaços de amplo e livre acesso, Mendonça (2007) e apoiados na utilização de affordances, Norman (2006).

A substituição de "brinquedos de playground" já conhecidos desta e de gerações passadas, por outros novos, projetados para a brincadeira e /ou para o exercício corporal (incluindo aí o motor e o cognitivo também) é salutar e pode renovar e contribuir para qualificar áreas livre de uso comum. Entretanto parece faltar informação no local de uso, de forma clara e objetiva que comunique as possibilidades de usos previstos, adequação etária, esclarecendo as categorias de atividades projetadas ou intencionais (seja por designers, fabricantes, órgãos públicos ou responsáveis pela implantação)

Projetar um equipamento para o espaço público requer o conhecimento que este novo objeto irá influenciar e também ser influenciado pelos comportamentos dos usuários e demais objetos e elementos existentes no local. Portanto espaços bem planejados com equipamentos adequados podem colaborar para diminuir a segregação social, aumentar o sentimento de pertencimento, valorizar e respeitar a criança como cidadã de hoje e do futuro, conforme conceitos de Santos (1996), Queiroga (2012) e Oliveira (2004).

Este trabalho deverá ser ampliado, por se tratar de um estudo exploratório com número limitado de respondentes, faz parte de um projeto de pesquisa que contemplará novos estudos de casos em praças e parques da cidade de São Paulo, para além de estabelecer comparações, confrontos e convergências entre os casos, situar também relações com o espaço livre para lazer, com o usuário e visando obter assim diretrizes de implantação e requisitos para o projeto deste produto. 
Espera-se que este estudo além de fomentar possibilidades de melhoria nos equipamentos existentes e gerar diretrizes para novos projetos neste segmento, possa também incentivar discussões sobre o tema do mobiliário urbano no espaço público.

\section{REFERÊNCIAS}

Associação Brasileira de Normas Técnicas. NBR 9283 - Mobiliário Urbano Classificação. Rio de Janeiro. 1986.

NBR 16071 - Playgrounds. São Paulo. 2012.

FLICK, Uwe. Introdução a metodologia de pesquisa: um guia para iniciantes. Porto Alegre: PENSO- ARTMED, 2012.

GATA, Daniela Della et al. Contextualizando as academias ao ar livre. Cadernos da escola de Educação e Humanidades, Curitiba, v. 1, n. 10, 2015. ISSN 1984-7068.

GRAY, David. E. Pesquisa no mundo real. 2. ed. Porto Alegre: Penso, 2012.

JOHN, Naiana.; REIS, Antonio T. Percepção, estética e uso do mobiliário urbano.

Gestão \& Tecnologia de Projetos, v. 5, n. 02, p. 181-206, nov 2010.

MAGNOLI, Miranda Maria E. Martinelli. O parque no desenho urbano. Paisagem Ambiente, p. 199-214, 2006.

MARINGÁ. ATI e API oferecem lazer e exercícios físicos para idosos e crianças, 2008. Disponivel em:

<http://www2.maringa.pr.gov.br/site////////index.php?sessao=aac7c9773055aa\&id= 6338>. Acesso em: 09 mai 2015.

MENDONÇA, Eneida Maria Souza. Apropriações do espaço público: alguns conceitos. Estudos e pesquisas em psicologia- UERJ, 2007.

MOURTHÉ, Claudia Rocha. Mobiliário Urbano. Rio de Janeiro: 2 AB editora, 2008.

NOMURA, Alessandra Ayumi. Estudo do Mobiliário Urbano no Centro Histórico de São Paulo. In: SILVA, José Carlos Plácido da.; SANTOS, Maria Cecília Loschiavo dos. Estudos em design nas universidades estaduais Unesp e USP. São paulo: UNESP, 2006. p. 187 207.

NORMAN, Donald. A. $O$ design do dia a dia. R.J: ROCCO, 2006.

OLIVEIRA, Claudia. O ambiente urbano e a formação da criança. São Paulo: Aleph, 2004.

QUEIROGA, Eugênio Fernandes. Dimensões públicas do espaço contemporâneo: resistências e transformações de territórios, paisagens e lugares urbanos brasileiros. São Paulo: Tese Livre Docência em Arquitetura e Urbanismo. 2012. p. 284.

SANTOS, Milton Almeida dos. A natureza do espaço: técnica e tempo, razão e emoção. São Paulo: Hucitec, 1996.

ZIOBER BRASIL. Catálogo de produtos, 2015. Disponivel em:

<http://www.zioberbrasil.com.br/kits.php?id=2>. Acesso em: 08 jan 2015. 